\title{
An unusual Pocillopora reef from the Late Miocene of Hispaniola
}

Received: 22 November 2010/Accepted: 18 January 2011/Published online: 17 February 2011

(C) Springer-Verlag 2011
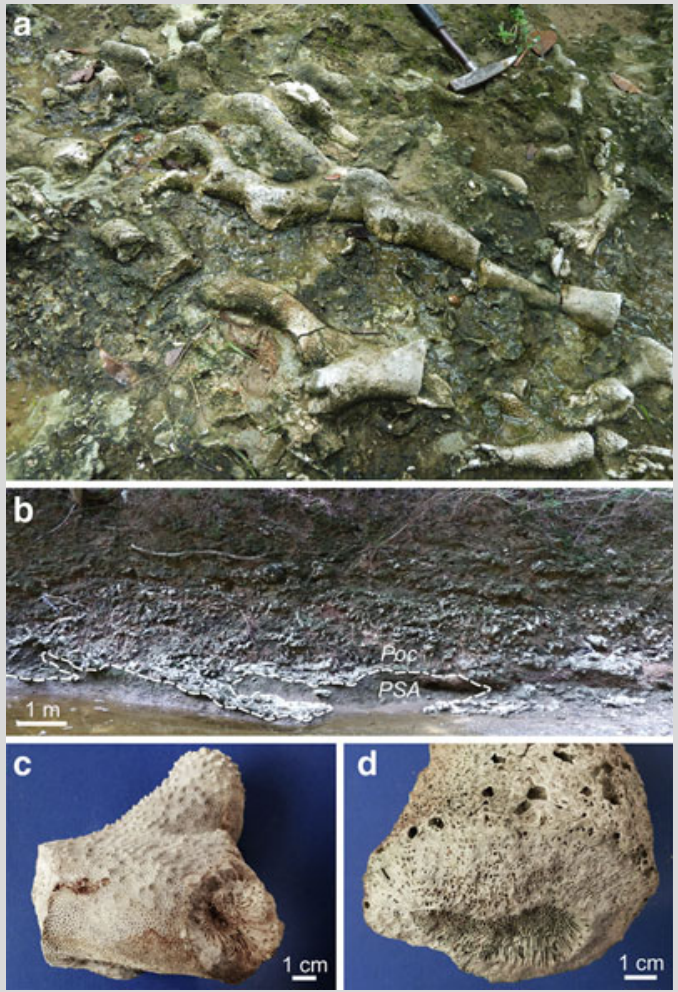

Fig. 1 a Robust-branching $P$. crassoramosa colonies in growth position, b Studied $P$. crassoramosa buildup incised by the Arroyo Bellaco river (Poc Pocillopora facies, PSA Porites-Stylophora-agariciid facies), c Detail of a coral branch showing the differences between upper and lower surface texture, d Growth increments in cross-section documenting asymmetric circumferential growth. The verrucae on this thick branch fragment are nearly removed due to boring and rasping bioerosion while the coral underside exhibits no traces of bioeroders
Pocillopora, a common reef coral in the present-day Indian Ocean, Red Sea, and Pacific Ocean, exhibits a wide range of environmentally controlled morphologic variation from submassive to bush-like uprightbranching colony forms (Veron 2000). Herein, we report on extinct reef-building $P$. crassoramosa from the Messinian Cercado Formation of the Cibao Basin in the Dominican Republic (N 19 $29^{\prime} 07.55^{\prime \prime}$, W $071^{\circ} 14^{\prime} 47.78^{\prime \prime}$; Maier et al. 2007) that has an unusual robust-branching growth morphology and horizontally disposed lifestyle - both not reported for recent Pocillopora.

Large branches of $P$. crassoramosa, many of which appear to be lying horizontally, are embedded in bioclastic silty marl (Fig. 1a) and form a 5-m-thick and 100-m-long buildup, which interfingers with an in situ coral thicket composed of upright standing, thin-branched Porites and Stylophora as well as plate-like agariciids (Fig. 1b).

Single Pocillopora colonies reach nearly 2 -m-length and consist of up to 10 -cm-thick branches (Fig. 1a). The undersurface of these branches is smooth while the upper surface exhibits bulbous outgrowths and is covered by wide-spaced verrucae (Fig. 1c). In cross-sections, the growth increments reveal asymmetric circumferential growth that is directed toward the textured side (Fig. 1d). Regrowth patterns such as changes in growth direction and/or shape are not observed. This indicates the horizontally lying branches are in place and implies a creeping mode of life. Accordingly, bioerosion was found preferentially on the upper sides of the corals (Fig. 1d).

It is assumed that the flat, spacious colony form is adapted for shallow, muddy bottoms because it is resistant to wave action and prevents the coral from sinking in the unstable substrate. The pronounced surface relief (Fig. 1c) may have favoured passive sediment removal due to steep gradients.

Acknowledgments Funding by the DFG through grant BR 1153/13-1 is gratefully acknowledged.

\section{References}

Maier KL, Klaus JS, McNeill DF, Budd AF (2007) A late Miocene low-nutrient window for Caribbean reef formation? Coral Reefs 26:635-639

Veron JEN (2000) Corals of the world, vol 2. Australian Institute of Marine Science, Townsville

M. Reuter ( $\square)$

Institute of Earth Sciences, University of Graz, Heinrichstr 26, 8010 Graz, Austria

e-mail: markus.reuter@uni-graz.at

T. C. Brachert · A. Böcker

Institute of Geophysics and Geology, University of Leipzig, Talstr 35, 04103 Leipzig, Germany

J. S. Klaus

Department of Geological Sciences, University of Miami, 43 Cox Science, Coral Gables, FL 33124-0401, USA

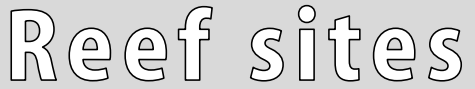

Coral Reefs (2011) 30:307 DOI $10.1007 / \mathrm{s} 00338-011-0728-4$ 